\title{
Associations of hormone replacement therapy and oral contraceptives with risk of colorectal cancer defined by clinicopathological factors, beta-catenin alterations, expression of cyclin D1, p53, and microsatellite-instability
}

Jenny Brändstedt ${ }^{1,2^{*}}$, Sakarias Wangefjord ${ }^{1,2}$, Björn Nodin ${ }^{1}$, Jakob Eberhard ${ }^{1}$, Karin Jirström ${ }^{1}$ and Jonas Manjerer,3,4

\begin{abstract}
Background: Postmenopausal hormone therapy (HRT) and oral contraceptive (OC) use have in several studies been reported to be associated with a decreased colorectal cancer (CRC) risk. However, data on the association between HRT and OC and risk of different clinicopathological and molecular subsets of CRC are lacking. The aim of this molecular pathological epidemiology study was therefore to evaluate the associations between HRT and OC use and risk of specific CRC subgroups, overall and by tumour site.

Method: In the population-based prospective cohort study Mamö Diet and Cancer, including 17035 women, 304 cases of CRC were diagnosed up until 31 December 2008. Immunohistochemical expression of beta-catenin, cyclin D1, p53 and MSI-screening status had previously been assessed in tissue microarrays with tumours from 280 cases. HRT was assessed as current use of combined HRT (CHRT) or unopposed oestrogen (ERT), and analysed among 12583 peri-and postmenopausal women. OC use was assessed as ever vs never use among all women in the cohort. A multivariate Cox regression model was applied to determine hazard ratios for risk of CRC, overall and according to molecular subgroups, in relation to HRT and OC use.

Results: There was no significantly reduced risk of CRC by CHRT or ERT use, however a reduced risk of T-stage 1-2 tumours was seen among CHRT users (HR: 0.24; 95\% Cl: 0.09-0.77).

Analysis stratified by tumour location revealed a reduced overall risk of rectal, but not colon, cancer among CHRT and ERT users, including T stage 1-2, lymph node negative, distant metastasis-free, cyclin D1 - and p53 negative tumours.

In unadjusted analysis, OC use was significantly associated with a reduced overall risk of CRC (HR: 0.56; 95\% Cl: 0.44-0.71), but this significance was not retained in adjusted analysis (HR: 1.05: 95\% Cl: 0.80-1.37). A similar risk reduction was seen for the majority of clinicopathological and molecular subgroups.
\end{abstract}

Conclusion: Our findings provide information on the relationship between use of HRT and OC and risk of clinicopathological and molecular subsets of CRC.

\footnotetext{
* Correspondence: jenny.brandstedt@med.lu.se

'Department of Clinical Sciences, Lund, Oncology and Pathology, Lund University, Skåne University Hospital, Lund, Sweden

2Department of Surgery, Skåne University Hospital, Malmö, Sweden

Full list of author information is available at the end of the article
} 


\section{Background}

Colorectal cancer (CRC) is the third most common cancer in westernized countries with approximately 1.2 million new cases being diagnosed every year [1]. The incidence is higher among men than women, and this sex difference is likely related to hormonal factors. Indeed, observational and experimental evidence suggests that sex hormones, particularly oestrogen, play a role in colorectal cancer pathogenesis [2]. Yet, the effect of oestrogen on the risk of $\mathrm{CRC}$ is not fully understood. CRC comprises a heterogeneous group of diseases with different sets of genetic and epigenetic alterations that develop through different carcinogenetic pathways, characterized by distinctive models of genetic instability, subsequent clinical manifestations, and pathological characteristics. In order to understand how a particular exposure influences the carcinogenic process, it is of great importance that the exposure of interest is studied in relation to molecular alterations. Molecular pathologic epidemiology (MPE), first proposed in 2010 [2], is a multidisciplinary field that investigates the relationship between exposure factors with molecular signatures of the tumours.

In a large meta-analysis conducted in 1999, Grodstein et al. [3] found that hormone replacement therapy (HRT) use was associated with a decreased risk of colon cancer of approximately 35\%. This association was further confirmed by the Women's Health Initiative (WHI) Clinical Trial [4,5], a randomized, double-blind placebo controlled clinical trial, where intervention with oestrogen plus progestin yielded a $44 \%$ reduction in incident CRC, while oestrogen alone did not appear to affect CRC risk. The California Teachers study revealed that the risk for colon cancer was 36\% lower among HRT users compared with never users, and the results did not differ by formulation [6]. Further, the risk was lower among recent HRT users with increasing duration between 5 and 15 years of use, but this risk reduction was was not seen in the longest duration group (more than 15 years of use) [6]. A metaanalysis of 18 observational studies showed a $20 \%$ reduction in colon cancer incidence among women having ever used HRT, and duration of HRT use did not influence risk estimates [7].

Hence, while epidemiological data support a protective effect of HRT on CRC, the associations between different combinations of HRT and CRC risk remain unclear. The results from the WHI, wherein unopposed estrogen did not appear to affect CRC risk, imply an important protective role of progestins, but the biological mechanisms underlying the effect of progestins in the colorectum are not well understood.

Colorectal carcinogenesis can be regarded as a complex process involving multiple genetic and epigenetic alterations [8,9]. Accumulating evidence suggests that the influence of aetiological factors may differ according to the carcinogenetic pathway. As traditional cancer epidemiology-approaches have not generally taken clinicopathological and key molecular characteristics, e.g. expression of beta-catenin, cyclin D1, p53 and mismatch repair proteins [10-13] into account, the impact of hormonal factors on CRC risk may be further clarified by doing so [14]. So far, studies on associations of HRT and molecular subgroups of CRC have been limited and inconsistent [15-17].

The epidemiological evidence for an association between oral contraceptives (OC) and CRC risk is also somewhat inconsistent in that some studies have suggested inverse associations [18-22], whereas others have found no associations [23-26]. A recent meta-analysis, summarising the results from seven cohort- and eleven case-control studies, reported a statistically significant risk reduction of $19 \%$ among ever users of OC compared with never users, although there was no clear risk reduction with increasing duration of use [27].

Taken together, the findings from these observational and experimental studies suggest that exogenous sex hormones may play an important role in colorectal carcinogenesis. The aim of this study was therefore to investigate the associations of postmenopausal HRT (combinations with oestrogen and progesterone as well as use of oestrogen alone) and $\mathrm{OC}$ use with CRC risk in the Malmö Diet and Cancer Study (MDCS), a large proscpective population based cohort study. In particular, we examined risk of CRC according to tumour site, TNMstage, expression of beta-catenin-, p 53 and cyclin D1, and microsatellite instability (MSI) screening status.

\section{Methods}

\section{The malmö diet and cancer study}

The Malmö Diet and Cancer Study (MDCS) is a population-based prospective cohort study of male and female residents in Malmö, Sweden, enrolled between 1991 and 1996. At the end of baseline examinations the total female cohort consisted of 17035 women, born 1923- 1950 [28]. A questionnaire assessed education, reproductive factors, exposure to OC, HRT, alcohol consumption and smoking habits. Weight and length was measured by a trained nurse and body mass index (BMI) was calculated as $\mathrm{kg} / \mathrm{m} 2$. Information on gynaecological surgery was retrieved from hospital records. Ethical permission for the MDCS (Ref. 51/90), and the present study (Ref. 530/2008), was obtained from the Ethics Committee at Lund University. Written informed consent was obtained from each participant.

\section{Exposure assessement}

Use of HRT was assessed in two ways. All participants were asked to keep a diary of medications. Moreover, medications were recorded in a questionnaire using an 
open-ended question on current use. Medications were coded according to the ATC classification. The present study has divided use of HRT into oestrogen alone (ERT), and combined HRT (CHRT), assessed as current use or not. The use of oral contraceptives was assessed as ever versus never use.

\section{Study population}

In total, 17035 women were included in the female cohort [28]. A woman was considered postmenopausal if she had undergone (I) bilateral oophorectomy or (II) hysterectomy, without bilateral oophorectomy, and if she was 55years of age or (III) if the above criteria were absent and she affirmed that her menstruations had ceased at least during 2years prior to baseline examinations.

A total of 12583 (73.9\%) women classified as peri- or postmenopausal at baseline made up for the study population in all HRT analyses. However, in the analyses related to $\mathrm{OC}$, both pre-, peri- and postmenopausal women were included in the analysis, i.e. the entire female cohort.

\section{End-point retrieval}

Incident cases of invasive CRC in the MDCS were identified through the Swedish Cancer Registry and vital status was determined by record linkage with the Swedish Cause of Death Registry. End of follow-up was 31 December 2009. Information on vital status and cause of death was obtained from the Swedish Cause of Death Registry until 31 December 2009. Time on study was defined as time from baseline to diagnosis, death or end of follow-up 31 December 2009. Median time from baseline until diagnosis was $8.6(\mathrm{SD}=4.3)$ years and the median follow-up time in the entire cohort was $13.7(\mathrm{SD}=3.2)$ years.

\section{Tumour characteristics}

Patient and tumour characteristics in the entire cohort have been described in detail previously [29-31]. In the female cohort, a total of 304 incident invasive CRC cases were identified. Forty-five cases were diagnosed with CRC before baseline examination, i.e. prevalent colorectal cancers, and therefore excluded from the study. Cases with other prevalent cancers were not excluded from the study. Of all incident CRC cases, 180 (59.2\%) had tumours located in the colon and 107 (35.2\%) had tumours located in the rectum. All tumours were histopathologically re-evaluated by a senior pathologist $(\mathrm{KJ})$.

According to the TNM classification, 33 (10.8\%) cases presented in T-stage 1, 30 (9.8\%) in T-stage 2, 159 (52.3\%) in T-stage 3 and 47 (15.4\%) in T-stage 4. One hundred and fifty two (50\%) cases presented with lymph node negative (N0) disease, $73(24.0 \%)$ had N1 (1-3 positive lymph nodes) and $33(10.9 \%)$ N2 (4 or more positive lymph nodes) disease. Two hundred and thirty seven
(78\%) patients did not have distant metastases (M0), and 56 (18.4\%) had M1 disease.

\section{Tissue microarray construction and immunohistochemistry}

Tissue microarrays (TMAs) had been constructed as previously described [29,30]. In brief, two $1.0 \mathrm{~mm}$ cores were taken from each tumour and mounted in a new recipient block using a semi-automated arraying device (TMArrayer, Pathology Devices, Westminster, MD, USA). Among the 304 incident CRC cases in the cohort, a total number of 280 tumours were suitable for TMAconstruction, and as demonstrated previously, there was no selection bias regarding the distribution of clinicopathological characteristics between the TMA cohort and the full cohort [29].

For immunohistochemical analysis, $4 \mu \mathrm{m}$ TMA-sections were automatically pre-treated using the PT-link system (DAKO, Glostrup, Denmark) and then stained in an Autostainer Plus (DAKO, Glostrup, Denmark). MSI screening status was evaluated as previously described [32], whereby tumour samples lacking nuclear staining of mismatch repair proteins MLH1, PMS2, MSH2 or MSH6 were considered to have a positive MSI screening status. Hereafter, tumours with a positive MSI screening status are referred to as MSI and tumours with negative MSI screening status are referred to as MSS.

Immunohistochemical staining of beta-catenin was performed and evaluated as previously described [33], whereby membranous staining was denoted as 0 (present) or 1 (absent), cytoplasmic staining intensity as $0-2$ and nuclear staining intensity as $0-2$. In this study, the analyses were limited to nuclear expression of beta-catenin. Cyclin D1 expression was evaluated as previously described [30] and p53 positivity was defined as $>=50 \%$ tumour cells with strong nuclear staining intensity in accordance with previous studies [34].

\section{Statistical methods}

A Cox proportional hazards analysis was applied in order to compare risk of CRC and CRC subgroups between ERT-, CHRT- and non HRT users, as well as between OC users and non OC users. For the subtype-specific analyses, the outcome variable was incident CRC with the molecular marker of interest; all other incident CRCs (including those with missing or unknown values for the molecular marker of interest) were considered censored observations at the date of diagnosis. This yielded relative risks (HR) with a $95 \%$ confidence interval. Time on study was used as the underlying time scale, defined as time from baseline to diagnosis, death or end of follow-up 31 December 2009. The proportional hazards assumption was confirmed by a log, - log plot [35]. Chi square test was applied for assessment of the distribution of investigative 
factors according to baseline characteristics. A case-tocase analysis examined the heterogeneity between different tumour subgroups regarding their association to anthropometric factors using an unconditional logistic regression model.

In the multivariate Cox analysis potential confounders were included, i.e. age (years), educational level, smoking habits, alcohol consumption and BMI (Table 1). All statistical analyses were conducted using SPSS version 20 (SPSS Inc., Chicago, IL, USA). A two-tailed p-value less than 0.05 was regarded as statistically significant.

\section{Results}

\section{Baseline characteristics}

The distribution of risk factors according to use and non use of HRT and OC is shown in Table 1. There were significant differences in the distribution of age, educational level, smoking status, alcohol consumption and BMI among users and non users of HRT and OC. Non HRT users were more often never smokers $(\mathrm{p}=<0.001)$, had a lower level of education ( $\mathrm{p}=<0.001)$, consumed less alcohol $(\mathrm{p}=<0.001)$, had a higher BMI $(\mathrm{p}=<0.001)$, and a higher age $(\mathrm{p}=<0.001)$, than HRT users. Additionally, ever users of OC were younger $(p=<0.001)$, had a higher level of education ( $p=<0.001)$, were more often smokers $(\mathrm{p}=<0.001)$, consumed more alcohol $(\mathrm{p}=<0.001)$, and had a lower BMI $(\mathrm{p}=<0.001)$, compared with never users.

\section{HRT use and risk of colorectal cancer subgroups}

There were no statistically significant associations between HRT use, combined (CHRT) or estrogen only (ERT), and overall CRC risk (Table 2). We found a significantly reduced risk of $\mathrm{T}$ stage 1 and 2 tumours among current users of CHRT (HR: 0.30; 95\% CI: 0.09-0.96). (Table 2). There were no associations between neither CHRT nor ERT use and risk of other particular subgroups of CRC (Tables 2 and 3).

When stratifying for cancer site, our results indicated significant associations of HRT use and an overall reduced risk of rectal, but not colon, cancer (HR: 0.32; 95\% CI: 0.14-0.71). Moreover, HRT use was significantly associated with $\mathrm{T}$ stage 1 and 2 (HR: 0.03; 95\%: 0.00-0.36), lymph node negative (HR: 0.22 ; 95\% CI: $0.06-0.77$ ) and nonmetastatic (HR: 0.42; 95\% CI: 0.18-0.98) rectal, but not colon, cancer (Table 4). We also found significant associations between HRT and cyclin D1 negative- (HR: 0.07; 95\% CI: 0.01-0.88) and p53 negative tumours (HR: 0.19; 95\% CI: 0.04-0.96) in the rectum (Table 5). Heterogeneity analysis revealed no significance between tumour subgoups.

Table 1 Distribution of risk factors in relation to HRT, ERT, and OC use

\begin{tabular}{|c|c|c|c|c|c|c|}
\hline Factor ( $\mathrm{n}$ of subjects with information) & Category & $\begin{array}{l}\text { Current CHRT } \\
n=3051 \\
(18.0 \%)\end{array}$ & $\begin{array}{l}\text { Current ERT } \\
\mathrm{n}=1375 \\
(8.0 \%)\end{array}$ & $\begin{array}{l}\text { HRT non use } \\
n=12519 \\
(73.9 \%)\end{array}$ & $\begin{array}{l}\text { Ever OC } \\
n=8353 \\
(49.1 \%)\end{array}$ & $\begin{array}{l}\text { Never OC } \\
n=8661 \\
(50.1 \%)\end{array}$ \\
\hline Age at baseline (16990) & Years* & 56.7 & 59.2 & 57.6 & 53.7 & 61.0 \\
\hline \multirow[t]{4}{*}{$p$} & & & & $<0.001$ & & $<0.001$ \\
\hline & Not completed school & $0.2^{\prime}$ & 0.2 & 0.9 & 0.3 & 1.2 \\
\hline & Elementary school (6-8 years) & 31.8 & 34.7 & 40.2 & 29.6 & 47.4 \\
\hline & 0-level college (9-10 years) & 33.4 & 34.4 & 29.7 & 32.5 & 28.3 \\
\hline \multirow{3}{*}{ Education (16947) } & A-level college (10-12 years) & 7.8 & 6.2 & 6.8 & 8.1 & 5.8 \\
\hline & 1 year university & 8.9 & 8.6 & 8.2 & 9.9 & 6.9 \\
\hline & University degree & 17.6 & 15.9 & 14.2 & 19.5 & 10.3 \\
\hline \multirow[t]{3}{*}{$p$} & & & & $<0.001$ & & $<0.001$ \\
\hline & Yes regularly & 23.7 & 20.3 & 23.7 & 27.8 & 20.6 \\
\hline & Yes occasionally & 4.8 & 4.0 & 4.2 & 4.9 & 3.8 \\
\hline \multirow{2}{*}{ Smoking status (16984) } & Former smoker & 31.2 & 18.0 & 26.9 & 31.6 & 25.0 \\
\hline & Never smoked & 40.0 & 44.7 & 45.2 & 35.8 & 54.2 \\
\hline \multicolumn{2}{|l|}{$p$} & & & $<0.001$ & & $<0.001$ \\
\hline Alcohol consumption (16990) & g/day* & 9.47 & 8.65 & 7.27 & 9.3 & 6.05 \\
\hline \multicolumn{2}{|l|}{$p$} & & & $<0.001$ & & $<0.001$ \\
\hline BMI (16964) & $\mathrm{Kg} / \mathrm{m}^{2^{*}}$ & 24.8 & 25.0 & 26.6 & 24.8 & 26.0 \\
\hline \multicolumn{2}{|l|}{$p$} & & & $<0.001$ & & $<0.001$ \\
\hline
\end{tabular}

*All values given in percentages unless otherwise indicated. 
Table 2 Risk of colorectal cancer, overall and according to clinicopathological factors, in relation to HRT and ERT use

\begin{tabular}{|c|c|c|c|c|c|c|}
\hline Tumour subgroups & HRT use & Number of cases & HR crude & $p$ & HR adjusted & $p$ \\
\hline & No & 236 & 1.00 & & 1.00 & \\
\hline \multirow[t]{3}{*}{ CRC } & ERT & 24 & $0.89(0.59-1.35)$ & 0.583 & $0.94(0.62-1.44)$ & 0.788 \\
\hline & CHRT & 41 & $0.74(0.53-1.03)$ & 0.076 & $0.94(0.67-1.31)$ & 0.701 \\
\hline & No & 54 & 1.00 & & 1.00 & \\
\hline \multirow[t]{3}{*}{ T stage $1 \& 2$} & ERT & 3 & $0.53(0.17-1.70)$ & 0.284 & $0.56(0.17-1.80)$ & 0.560 \\
\hline & CHRT & 3 & $0.24(0.09-0.77)$ & 0.016 & $0.30(0.09-0.96)$ & 0.043 \\
\hline & No & 156 & 1.00 & & 1.00 & \\
\hline \multirow[t]{3}{*}{ T stage $3 \& 4$} & ERT & 17 & $0.93(0.56-1.52)$ & 0.761 & $1.01(0.61-1.67)$ & 0.966 \\
\hline & CHRT & 32 & $0.87(0.59-1.27)$ & 0.471 & $1.14(0.77-1.68)$ & 0.511 \\
\hline & No & 119 & 1.00 & & 1.00 & \\
\hline \multirow[t]{3}{*}{ No } & ERT & 14 & $1.03(0.59-1.79)$ & 0.912 & $1.15(0.66-2.01)$ & 0.615 \\
\hline & CHRT & 22 & $0.79(0.50-1.24)$ & 0.302 & $1.05(0.66-1.67)$ & 0.838 \\
\hline & No & 79 & 1.00 & & 1.00 & \\
\hline \multirow[t]{3}{*}{$N 1 \& N 2$} & ERT & 7 & $0.75(0.35-1.63)$ & 0.471 & $0.78(0.36-1.68)$ & 0.522 \\
\hline & CHRT & 15 & $0.81(0.47-1.40)$ & 0.449 & $0.95(0.54-1.67)$ & 0.860 \\
\hline & No & 181 & 1.00 & & 1.00 & \\
\hline \multirow[t]{3}{*}{ MO } & ERT & 20 & $0.96(0.61-1.52)$ & 0.863 & $1.04(0.66-1.66)$ & 0.861 \\
\hline & CHRT & 34 & $0.80(0.55-1.15)$ & 0.232 & $1.03(0.71-1.49)$ & 0.893 \\
\hline & No & 45 & 1.00 & & 1.00 & \\
\hline \multirow[t]{2}{*}{ M1 } & ERT & 4 & $0.78(028-2.16)$ & 0.632 & $0.77(0.28-2.16)$ & 0.625 \\
\hline & CHRT & 7 & $0.66(0.30-1.47)$ & 0.311 & $0.80(0.36-1.80)$ & 0.589 \\
\hline
\end{tabular}

Adjusted for age, bmi, educational level, smoking habits and alcohol consumption.

\section{Oral contreceptive use and risk of colorectal cancer subgroups}

As demonstrated in Table 6, there was a statistically significant inverse association between ever-use of $\mathrm{OC}$ and overall CRC risk (HR: 0.56; 95\% CI: 0.44-0.71) in unadjusted analysis. However, after adjustment for wellestablished risk factors of CRC, i.e. age, BMI, alcohol consumption, smoking habits and educational level, this significant association was lost.

Similar statistically significant inverse associations were seen between OC use and the majority of clinicopathological and molecular subgroups, except for lymph node positive disease, negative nuclear betacatenin expression and MSS tumours (Table 6). Again, no statistically significant results were seen after adjustment for established risk factors.

In the analysis stratified for cancer site, a significantly increased risk was found of lymph node positive (HR: 1.81 95\% CI: 1.00-3.28) and non-metastatic disease (HR: 1.55; 95\% CI: $1.00-2.40)$, as well as for cyclin D1 positive tumours (HR: 1.62 95\% CI: 1.04-2.51) in the colon (Table 7). No associations were found between $\mathrm{OC}$ use and specific subgroups of rectal cancer, or overall risk for colon or rectal cancer. No significant heterogeneity was found between tumour subgoups.

\section{Discussion}

In this prospective cohort study, we present data on associations between use of HRT and OC and overall risk of $\mathrm{CRC}$, as well as risk of different clinicopathological and molecular subgroups thereof. It should be pointed out that, due to the limited number of cases available in the subgroup analyses, the associations were rather modest. In the present study, we could not demonstrate the expected risk reduction of HRT use and CRC use, which is in contrast with findings from several previous studies [3,36-39], as well as with three large meta-analyses, demonstrating a significantly lower incidence of CRC with use of combined hormone therapy [7,40,41]. As regards associations with TNM stage in the entire cohort, we found a significantly reduced risk of T-stage 1 and 2 tumours, but not of any other particular subgroups of CRC. When stratifying for cancer site, we found a significant risk reduction for CHRT use and overall risk of rectal, but not colon, cancer. Significant associations were also seen between CHRT use and risk of T-stage 1 and 2 tumours, lymph node negativity, non metastatic disease, cyclin D1 negativity and p53 negativity for tumours located in the rectum. Again, it must be emphasized that these results are based on a very limited number of cases. Previous studies on HRT and risk of colon and 
Table 3 Risk of colorectal cancer and molecular subgroups in relation to HRT and ERT use

\begin{tabular}{|c|c|c|c|c|c|c|}
\hline Tumour subgroups & HRT use & $\mathrm{n}$ & HR crude & $p$ & HR adjusted & $p$ \\
\hline & No & 126 & 1.00 & & 1.00 & \\
\hline \multirow[t]{3}{*}{ beta-catenin +} & ERT & 13 & $0.93(0.52-1.64)$ & 0.790 & $1.04(0.58-1.84)$ & 0.902 \\
\hline & CHRT & 19 & $0.64(0.40-1.04)$ & 0.074 & $0.87(0.53-1.42)$ & 0.868 \\
\hline & No & 80 & 1.00 & & 1.00 & \\
\hline \multirow[t]{3}{*}{ beta-catenin - } & ERT & 7 & $0.76(0.35-1.65)$ & 0.490 & $0.77(0.36-1.68)$ & 0.516 \\
\hline & CHRT & 13 & $0.69(0.39-1.24)$ & 0.217 & $0.83(0.46-1.50)$ & 0.533 \\
\hline & No & 173 & 1.00 & & 1.00 & \\
\hline \multirow[t]{3}{*}{ cyclin D1 + } & ERT & 16 & $0.81(0.49-1.35)$ & 0.416 & $0.87(0.52-145)$ & 0.591 \\
\hline & CHRT & 29 & $0.72(0.48-1.06)$ & 0.096 & 0.93(0.63-1.39) & 0.734 \\
\hline & No & 31 & 1.00 & & 1.00 & \\
\hline \multirow[t]{3}{*}{ cyclin D1 - } & ERT & 4 & $1.16(0.41-3.28)$ & 0.782 & $1.26(0.44-3.59)$ & 0.661 \\
\hline & CHRT & 5 & $0.68(0.27-1.75)$ & 0.425 & $0.84(0.32-2.19)$ & 0.721 \\
\hline & No & 99 & 1.00 & & 1.00 & \\
\hline \multirow[t]{3}{*}{ p53+ } & ERT & 11 & $0.98(0.53-1.83)$ & 0.956 & 1.07(0.57-1.99) & 0.843 \\
\hline & CHRT & 18 & $0.78(0.47-1.29)$ & 0.334 & $1.00(0.59-1.65)$ & 0.970 \\
\hline & No & 107 & 1.00 & & 1.00 & \\
\hline \multirow[t]{3}{*}{ p53- } & ERT & 9 & $0.74(0.37-1.45)$ & 0.374 & $0.79(0.40-1.55)$ & 0.488 \\
\hline & CHRT & 16 & $0.63(0.38-1.07)$ & 0.089 & $0.84(0.49-1.42)$ & 0.508 \\
\hline & No & 38 & 1.00 & & 1.00 & \\
\hline \multirow[t]{3}{*}{ MSI } & ERT & 1 & $0.23(0.03-1.63)$ & 0.140 & $0.24(0.03-1.72)$ & 0.154 \\
\hline & CHRT & 5 & $0.56(0.22-1.43)$ & 0.225 & $0.80(0.31-2.06)$ & 0.649 \\
\hline & No & 164 & 1.00 & & 1.00 & \\
\hline \multirow[t]{2}{*}{ MSS } & ERT & 18 & $0.97(0.60-1.58)$ & 0.903 & $1.06(0.65-1.72)$ & 0.829 \\
\hline & CHRT & 28 & $0.73(0.49-1.09)$ & 0.120 & $0.92(0.61-1.39)$ & 0.700 \\
\hline
\end{tabular}

Adjusted for age, bmi, educational level, smoking habits and alcohol consumption.

rectal cancer, respectively, are sparse and present diverging results. Most studies report a similar risk reduction for both colon- and rectal cancer [40-42], however at least two studies reported a significantly lower risk of colon, but not rectal, cancer, with the use of HRT [6,37]. The potential biological mechanisms underlying the differences in risk related to location remain unclear.

The most frequently cited study on this subject is the Women's Health Initiative Trial [4], that demonstrated a $44 \%$ risk reduction with continous combined estrogen plus progesterin therapy compared to the placebo group, whereas unopposed estrogen therapy was not associated with a decreased CRC risk. However, despite the convincing risk reduction of $44 \%$, the WHI clinical trial raises several questions. Firstly, follow-up time was only 5.2 years in this trial, and consequently, information on long term effects is lacking. Secondly, despite the fact that women taking HRT at the time of diagnosis had a larger extent of lymph node positive disease and more advanced clinical stage, mortality from CRC was not decreased in this category. Therefore, the clinical relevance of these results needs to be further discussed.
Concerning the effects of combined versus unopposed estrogen therapy, results are diverging. The WHI presented no risk reduction of unopposed estrogen, which is in line with the findings by Newcomb et al. [37], who reported an inverse association between CRC risk and current combined HRT in a large case-control study, but no association with unopposed estrogen therapy. In contrast to these findings, both the California Teacher Study and Campbell et al. reported a lower risk of CRC among ever users of HRT, but no difference in risk by formulation [20].

Few previous studies have addressed the possible interaction between hormone therapy use and CRC risk in relation to clinical disease stage at diagnosis. Grodstein et al. reported a similar risk reduction with hormone therapy for higher and lower stages [43]. In the California Teachers study, the association between HRT and reduced CRC risk was stronger for more advanced stages [6]. However, in both the California Teachers Study, and the Womens Health Trial, the difference in clinical stage at time of diagnosis may be due to the high level of screening-detected cases among these patients, hence being in an earlier stage 
Table 4 Risk of CRC and clinicopathological subgrops in relation to HRT and ERT use in colon and rectum

\begin{tabular}{|c|c|c|c|c|c|c|c|c|c|c|c|}
\hline \multirow[b]{2}{*}{ Tumour subgroups } & \multirow[b]{2}{*}{ HRT use } & \multicolumn{5}{|c|}{ Colon } & \multicolumn{5}{|c|}{ Rectum } \\
\hline & & $\mathrm{n}$ & HR crude & $p$ & HR adjusted & $p$ & $\mathrm{n}$ & HR crude & $p$ & HR adjusted & $p$ \\
\hline & No & 150 & 1.00 & & 1.00 & & 81 & 1.00 & & 1.00 & \\
\hline \multirow[t]{3}{*}{ CRC } & ERT & 15 & $1.21(0.71-2.06)$ & 0.488 & $1.17(0.67-2.02)$ & 0.584 & 8 & $0.49(0.23-1.03)$ & 0.061 & $0.38(0.17-0.86)$ & 0.020 \\
\hline & CHRT & 28 & 1.04(0.68-1.57) & 0.873 & $1.16(0.74-1.80)$ & 0.521 & 13 & $0.44(0.23-0.86)$ & 0.017 & $0.32(0.14-0.71)$ & 0.005 \\
\hline & No & 27 & 1.00 & & 1.00 & & 24 & 1.00 & & 1.00 & \\
\hline \multirow[t]{3}{*}{ T stage $1 \& 2$} & ERT & 1 & $0.52(0.07-3.89)$ & 0.525 & $0.34(0.04-2.70)$ & 0.308 & 2 & $0.32(0.07-1.45)$ & 0.138 & $0.11(0.02-0.67)$ & 0.017 \\
\hline & CHRT & 1 & $0.21(0.03-1.54)$ & 0.125 & $0.24(0.03-1.90)$ & 0.178 & 2 & $0.09(0.01-0.76)$ & 0.026 & $0.03(0.00-0.36)$ & 0.031 \\
\hline & No & 117 & 1.00 & & 1.00 & & 42 & 1.00 & & 1.00 & \\
\hline \multirow[t]{3}{*}{ T stage $3 \& 4$} & ERT & 13 & $1.29(0.73-2.30)$ & 0.381 & $1.30(0.72-2.35)$ & 0.384 & 4 & $0.53(0.19-1.48)$ & 0.223 & $0.51(0.17-1.55)$ & 0.233 \\
\hline & CHRT & 24 & $1.17(0.75-1.83)$ & 0.486 & $1.27(0.78-2.04)$ & 0.335 & 8 & $0.72(0.33-1.58)$ & 0.414 & $0.74(0.28-1.94)$ & 0.533 \\
\hline & No & 72 & 1.00 & & 1.00 & & 45 & 1.00 & & 1.00 & \\
\hline \multirow[t]{3}{*}{ No } & ERT & 11 & $1.72(0.91-3.26)$ & 0.096 & $1.54(0.79-3.00)$ & 0.203 & 3 & $0.36(0.11-1.20)$ & 0.097 & $0.31(0.08-1.13)$ & 0.076 \\
\hline & CHRT & 16 & $1.20(0.70-2.08)$ & 0.508 & $1.49(0.83-2.67)$ & 0.183 & 6 & $0.29(0.10-0.85)$ & 0.024 & $0.22(0.06-0.77)$ & 0.222 \\
\hline & No & 64 & 1.00 & & 1.00 & & 18 & 1.00 & & 1.00 & \\
\hline \multirow[t]{3}{*}{$N 1 \& N 2$} & ERT & 4 & $0.76(0.28-2.10)$ & 0.596 & $0.79(0.28-2.23)$ & 0.659 & 3 & $1.03(0.30-3.56)$ & 0.959 & $1.00(0.26-3.92)$ & 1.000 \\
\hline & CHRT & 10 & $0.90(0.46-1.77)$ & 0.762 & $0.79(0.37-1.65)$ & 0.522 & 5 & $1.18(0.42-3.34)$ & 0.757 & $1.00(0.27-3.73)$ & 1.000 \\
\hline & No & 114 & 1.00 & & 1.00 & & 64 & 1.00 & & 1.00 & \\
\hline \multirow[t]{3}{*}{ MO } & ERT & 13 & $1.38(0.77-2.46)$ & 0.277 & $1.25(0.69-2.26)$ & 0.471 & 7 & $0.54(0.24-1.20)$ & 0.130 & $0.43(0.18-1.03)$ & 0.057 \\
\hline & CHRT & 22 & $1.10(0.69-1.74)$ & 0.695 & $1.21(0.74-1.97)$ & 0.446 & 12 & $0.54(0.29-1.09)$ & 0.084 & $0.42(0.18-0.98)$ & 0.044 \\
\hline & No & 32 & 1.00 & & 1.00 & & 13 & 1.00 & & 1.00 & \\
\hline \multirow[t]{2}{*}{ M1 } & ERT & 3 & $1.04(0.32-3.40)$ & 0.953 & $1.24(0.37-4.16)$ & 0.732 & 1 & $0.31(0.04-2.48)$ & 0.269 & $0.32(0.03-3.24)$ & 0.335 \\
\hline & CHRT & 6 & $1.06(0.44-2.56)$ & 0.900 & $1.13(0.42-3.00)$ & 0.809 & 1 & $0.14(0.02-1.22)$ & 0.075 & $0.06(0.00-1.18)$ & 0.064 \\
\hline
\end{tabular}

Adjusted for age, bmi, educational level, smoking habits and alcohol consumption.

at diagnosis. In the present study, we found a significantly reduced risk of $\mathrm{T}$ stage 1 and 2 tumours among current users of CHRT, and for rectal cancers this risk reduction was also seen for lymph node negative and non-metastatic disease, i.e. less advanced clinical stages.

The relationship between postmenopausal hormone therapy and molecular subtypes of CRC has not yet been thoroughly studied $[15,44]$. However, a recent study investigated the relationship between HRT use and MSI, BRAF and CIMP status of the tumours [15], whereby HRT (ever vs never use) was inversely associated with overall CRC risk, lower risk for MSI-L/MSS tumours and borderline significantly lower risks for CIMP-negative and BRAF-wildtype tumours, suggesting that HRT may have more pronounced inhibitory effects on the"traditional" pathway, as compared to the serrated or alternate pathways, of colorectal carcinogenesis. Additionally, Lin et al. found no associations between HRT and CRC risk according to MSI or p 53 status [44]. In this present study, we did not find any associations between current use of HRT and risk of CRC according to molecular features of the tumours in the overall analysis. However, as already mentioned, in stratified analysis according to tumour location, we found a lower risk of cyclin D1 and p53 negative tumours in the rectum.

When evaluating the associations between ever use of $\mathrm{OC}$ and CRC risk, we found no significant results in the analyses adjusted for established risk factors of CRC. However, in the unadjusted analysis, a significant risk reduction was seen for OC use and all CRC subgroups, except lymph-node positive disease, negative nuclear beta-catenin expression and MSS tumours. The analysis was repeated including one additional covariate in separate models. The association between OC and all studied subgroups remained statistically significant in all models except the one including age at baseline, and also after inclusion of menopausal status in the analysis (data not shown).

For cancers located in the colon, contrasting associations were found, with an increased risk of lymph nodepositive and non-metastatic tumours, as well as for cyclin D1 positive tumours.

The epidemiologic evidence for a causal link between OC and CRC risk has not been consistent [19-22,24-26]. To our knowledge, only two previous studies have adressed the question whether this potential association is influenced by molecular features of the tumours. 
Table 5 Risk of CRC and molecular subgroups in relation to HRT and ERT use in colon and rectum

\begin{tabular}{|c|c|c|c|c|c|c|c|c|c|c|c|}
\hline \multirow[b]{2}{*}{ Tumour subgroups } & \multirow[b]{2}{*}{ HRT use } & \multicolumn{5}{|c|}{ Colon } & \multicolumn{5}{|c|}{ Rectum } \\
\hline & & $\mathrm{n}$ & HR crude & $p$ & HR adjusted & $p$ & $n$ & HR crude & $p$ & HR adjusted & $p$ \\
\hline & No & 68 & 1.00 & & 1.00 & & 51 & 1.00 & & 1.00 & \\
\hline \multirow[t]{3}{*}{ beta-catenin + } & ERT & 9 & $1.62(0.80-3.26)$ & 0.180 & $1.52(0.74-3.16)$ & 0.257 & 4 & $0.38(0.14-1.09)$ & 0.073 & $1.00(0.45-2.25)$ & 1.000 \\
\hline & CHRT & 11 & $0.88(0.46-1.67)$ & 0.696 & $0.96(0.48-1.91)$ & 0.910 & 8 & $0.44(0.19-1.02)$ & 0.054 & $1.00(0.44-2.26)$ & 1.000 \\
\hline & No & 64 & 1.00 & & 1.00 & & 17 & 1.00 & & 1.00 & \\
\hline \multirow[t]{3}{*}{ beta-catenin - } & ERT & 4 & $0.76(0.27-2.09)$ & 0.588 & $0.71(0.25-1.97)$ & 0.506 & 3 & $0.87(0.24-3.12)$ & 0.833 & $1.00(0.27-3.73)$ & 1.000 \\
\hline & CHRT & 10 & $0.91(0.46-1.78)$ & 0.779 & $0.92(0.45-1.88)$ & 0.808 & 3 & $0.41(0.09-1.83)$ & 0.242 & $1.00(0.25-3.95)$ & 1.000 \\
\hline & No & 120 & 1.00 & & 1.00 & & 50 & 1.00 & & 1.00 & \\
\hline \multirow[t]{3}{*}{ cyclin D1 + } & ERT & 10 & $1.04(0.54-1.98)$ & 0.917 & $0.96(0.49-1.86)$ & 0.895 & 6 & $0.56(0.23-1.34)$ & 0.189 & $0.44(0.17-1.14)$ & 0.091 \\
\hline & CHRT & 18 & $0.86(0.52-1.42)$ & 0.557 & $0.95(0.56-1.62)$ & 0.854 & 11 & $0.60(0.28-1.28)$ & 0.188 & $0.51(0.21-1.24)$ & 0.135 \\
\hline & No & 15 & 1.00 & & 1.00 & & 16 & 1.00 & & 1.00 & \\
\hline \multirow[t]{3}{*}{ cyclin D1 - } & ERT & 3 & $2.05(0.59-7.10)$ & 0.260 & $2.34(0.65-8.44)$ & 0.196 & 1 & $0.37(0.05-2.81)$ & 0.334 & $0.28(0.03-2.27)$ & 0.232 \\
\hline & CHRT & 4 & $1.33(0.44-4.05)$ & 0.615 & $1.50(0.46-4.94)$ & 0.504 & 1 & $0.19(0.02-1.56)$ & 0.124 & $0.07(0.01-0.88)$ & 0.039 \\
\hline & No & 54 & 1.00 & & 1.00 & & 40 & 1.00 & & 1.00 & \\
\hline \multirow[t]{3}{*}{ p53 + } & ERT & 6 & $1.38(0.59-3.24)$ & 0.454 & $1.27(0.53-3.02)$ & 0.588 & 5 & $0.54(0.21-1.41)$ & 0.208 & $1.00(0.43-2.35)$ & 1.000 \\
\hline & CHRT & 9 & $0.94(0.46-1.92)$ & 0.869 & $1.02(0.48-2.20)$ & 0.951 & 9 & $0.56(0.25-1.27)$ & 0.168 & $1.00(0.42-2.40)$ & 1.000 \\
\hline & No & 82 & 1.00 & & 1.00 & & 26 & 1.00 & & 1.00 & \\
\hline \multirow[t]{3}{*}{ p53 - } & ERT & 7 & $1.02(0.47-2.21)$ & 0.968 & $0.95(0.43-2.11)$ & 0.903 & 2 & $0.47(0.11-2.02)$ & 0.308 & $0.23(0.05-1.18)$ & 0.078 \\
\hline & CHRT & 13 & $0.89(0.49-1.61)$ & 0.703 & $1.00(0.54-1.86)$ & 0.996 & 3 & $0.36(0.09-1.54)$ & 0.170 & $0.19(0.04-0.96)$ & 0.044 \\
\hline & No & 36 & 1.00 & & 1.00 & & 2 & 1.00 & & 1.00 & \\
\hline \multirow[t]{3}{*}{ MSI } & ERT & 1 & $0.36(0.05-2.67)$ & 0.320 & $0.28(0.04-2.08)$ & 0.212 & 0 & - & & - & \\
\hline & CHRT & 5 & $0.84(0.32-2.16)$ & 0.710 & $0.90(0.34-2.40)$ & 0.832 & 0 & - & & - & \\
\hline & No & 97 & 1.00 & & 1.00 & & 64 & 1.00 & & 1.00 & \\
\hline \multirow[t]{2}{*}{ MSS } & ERT & 11 & $1.35(0.72-2.53)$ & 0.349 & $1.36(0.71-2.60)$ & 0.352 & 7 & $0.54(0.24-1.22)$ & 0.138 & $1.00(0.49-2.03)$ & 1.000 \\
\hline & CHRT & 17 & $0.98(0.58-1.65)$ & 0.943 & 1.08(0.62-1.89) & 0.789 & 11 & $0.46(0.22-0.97)$ & 0.041 & $1.00(0.49-2.05)$ & 1.000 \\
\hline
\end{tabular}

Adjusted for age, bmi, educational level, smoking habits and alcohol consumption.

Newcomb et al. have previously studied the association between HRT and MSI status of the tumours and found no association with MSI high tumours, but a risk reduction of $20 \%$ for MSI-low/MSS tumours [16,45], and no difference in risk according to tumour location. Additionally, Slattery et al. demonstrated a lower risk of MSI positive tumours among both recent HRT users and OC users [16].

Based on results from emerging translational research, several molecular models have been described to account for the clinicopathological heterogeneity in colorectal carcinogenesis [10-12,34,46,47]. The potential mechanisms by which hormone therapy use reduces risk of CRC development remain unclear. Experimental studies on mice and cell lines have shown that oestrogen- or progesteroneactivated signaling leads to growth inhibiting effects on colon cancer cells by upregulating several cell cycle regulators such as p 21, p27 and p53 $[48,49]$. It has also been proposed that estrogen treatment maintains genomic stability in colonic epithelial cells through upregulation of mismatch repair genes [16,50]. Epigenetic events may also play an important role, as estrogen may be a key factor in the pathway leading to the CpG-island hypermethylation (CIMP) phenotype [51].

General strengths of our study include the populationbased, prospective design, the ability to control for multiple potential confounding factors in multivariate risk models and the molecular pathological epidemiology approach linking life style exposures to different tumour markers [14].

Information on HRT use was provided from two different sources, a diary as well as a questionnaire, thus optimising the opportunity to include all HRT-users and minimising the number of under-reporters. We consider our data on HRT to be valid and reliable. This study used two HRT categories, namely current and non-users, which is a limitation as the non-user cohort probably included former users. Such a misclassification is likely to lead to an attenuation of risks and, if anything, observed risks may be underestimated. Regarding exposure to OC, the risk of misclassification is probably lower, since we have used ever vs never use, and most women are peri- or 
Table 6 Risk of colorectal cancer, overall and according to clinicopathological factors, in relation to oral contraceptive (OC) use

\begin{tabular}{|c|c|c|c|c|c|c|}
\hline Tumour subgroups & OC use & $\mathbf{n}$ & HR crude & $p$ & HR adjusted & $p$ \\
\hline \multirow{2}{*}{ CRC } & No & 194 & 1.00 & & 1.00 & \\
\hline & OC & 107 & $0.56(0.44-0.71)$ & $<0.001$ & $1.05(0.80-1.37)$ & 0.738 \\
\hline \multirow{2}{*}{ T stage $1 \& 2$} & No & 45 & 1.00 & & 1.00 & \\
\hline & OC & 17 & $0.39(0.22-0.68)$ & 0.001 & $0.69(0.37-1.28)$ & 0.239 \\
\hline \multirow{2}{*}{ T stage $3 \& 4$} & No & 127 & 1.00 & & 1.00 & \\
\hline & OC & 77 & $0.62(0.47-0.82)$ & 0.001 & $1.21(0.87-1.67)$ & 0.254 \\
\hline \multirow{2}{*}{ NO } & No & 105 & 1.00 & & 1.00 & \\
\hline & OC & 46 & $0.45(0.32-0.63)$ & $<0.001$ & $0.82(0.56-1.22)$ & 0.328 \\
\hline \multirow{2}{*}{ N1 \& N2 } & No & 60 & 1.00 & & 1.00 & \\
\hline & OC & 45 & $0.78(0.52-1.13)$ & 0.176 & $1.36(0.88-2.11)$ & 0.173 \\
\hline \multirow{2}{*}{ MO } & No & 150 & 1.00 & & 1.00 & \\
\hline & OC & 85 & $0.58(0.44-0.75)$ & $<0.001$ & $1.05(0.78-1.42)$ & 0.744 \\
\hline \multirow{2}{*}{ M1 } & No & 38 & 1.00 & & 1.00 & \\
\hline & OC & 17 & $0.46(0.26-0.81)$ & 0.007 & $0.90(0.47-1.70)$ & 0.734 \\
\hline \multirow{2}{*}{ beta-catenin+ } & No & 105 & 1.00 & & 1.00 & \\
\hline & OC & 51 & $0.50(0.35-0.70)$ & $<0.001$ & $0.97(0.66-1.41)$ & 0.853 \\
\hline \multirow{2}{*}{ beta-catenin- } & No & 61 & 1.00 & & 1.00 & \\
\hline & OC & 42 & $0.70(0.47-1.04)$ & 0.076 & $1.31(0.84-2.05)$ & 0.232 \\
\hline \multirow{2}{*}{ cyclin D1+ } & No & 138 & 1.00 & & 1.00 & \\
\hline & OC & 75 & $0.55(0.42-0.74)$ & $<0.001$ & $1.16(0.85-1.60)$ & 0.351 \\
\hline \multirow{2}{*}{ cyclin D1- } & No & 30 & 1.00 & & 1.00 & \\
\hline & OC & 15 & $0.51(0.27-0.94)$ & 0.032 & $0.63(0.32-1.27)$ & 0.199 \\
\hline \multirow{2}{*}{ p53+ } & No & 81 & 1.00 & & 1.00 & \\
\hline & OC & 46 & $0.58(0.41-0.83)$ & 0.003 & $1.06(0.70-1.60)$ & 0.744 \\
\hline \multirow{2}{*}{ p53- } & No & 88 & 1.00 & & 1.00 & \\
\hline & OC & 45 & $0.52(0.36-0.74)$ & $<0.001$ & $1.04(0.70-1.56)$ & 0.840 \\
\hline \multirow{2}{*}{ MSI } & No & 28 & 1.00 & & 1.00 & \\
\hline & $O C$ & 17 & $0.62(0.34-1.13)$ & 0.117 & $1.78(0.92-3.47)$ & 0.088 \\
\hline \multirow{2}{*}{ MSS } & No & 136 & 1.00 & & 1.00 & \\
\hline & OC & 74 & $0.56(0.42-0.74)$ & $<0.001$ & $0.98(0.71-1.36)$ & 0.912 \\
\hline
\end{tabular}

Adjusted for age, bmi, educational level, smoking habits and alcohol consumption.

postmenopausal at baseline and will most probably not start treatment with oral contraceptives by that time. Information on duration of exposure of both HRT and $\mathrm{OC}$ is lacking in this study, which may have provided deeper knowledge on the associations with CRC risk.

A limitation to the present study is the relatively small number of cases in some subgroups, particularly in the analyses stratified for tumour location. This generates large confidence intervals and, subsequently, low statistical power and the possibility that some of the non-significant findings may have been caused by a potential type II error. Therefore, we regard our study as primarily explorative. To our best knowledge, no studies have described the associations of HRT and OC use and risk of CRC defined by the herein investigated biomarkers. Furthermore, we have no à priori hypothesis on the direction of the possible associations. Given the discovery-driven nature of this study, we consider it important not to increase the risk of a potential type II error by adjusting p-values. Instead, any identified associations will need confirmation in future studies.

Although there are several challenges to molecular epidemiological pathology studies, for example multiple hypothesis testing, misclassification of tumour endpoints, and sample size, the discipline also has unique strengths. MPE can provide insights into mechanisms related to both CRC initiation and progression, in order to optimize personalised prevention and therapy strategies [52]. By 
Table 7 Risk of colorectal cancer, overall and according to clinicopathological factors, in relation to oral contraceptive $(O C)$ use in colon and rectum

\begin{tabular}{|c|c|c|c|c|c|c|c|c|c|c|c|}
\hline \multirow[b]{2}{*}{ Tumour subgroups } & \multirow[b]{2}{*}{ OC use } & \multicolumn{5}{|c|}{ Colon } & \multicolumn{5}{|c|}{ Rectum } \\
\hline & & $\mathbf{n}$ & HR crude & $p$ & HR adjusted & $p$ & $\mathbf{n}$ & HR crude & $p$ & HR adjusted & $p$ \\
\hline \multirow{2}{*}{ CRC } & No & 116 & 1.00 & & 1.00 & & 69 & 1.00 & & 1.00 & \\
\hline & OC & 59 & $1.00(0.73-1.37)$ & 0.998 & $1.41(0.96-2.08)$ & 0.080 & 37 & $1.02(0.68-1.53)$ & 0.934 & $0.97(0.59-1.60)$ & 0.900 \\
\hline \multirow{2}{*}{ T stage $1 \& 2$} & No & 22 & 1.00 & & 1.00 & & 21 & 1.00 & & 1.00 & \\
\hline & $\mathrm{OC}$ & 8 & $0.72(0.32-1.62)$ & 0.422 & $1.43(0.56-3.66)$ & 0.462 & 8 & $0.76(0.33-1.76)$ & 0.521 & $0.67(0.23-1.89)$ & 0.445 \\
\hline \multirow{2}{*}{ T stage $3 \& 4$} & No & 89 & 1.00 & & 1.00 & & 34 & 1.00 & & 1.00 & \\
\hline & OC & 49 & $1.08(0.76-1.54)$ & 0.655 & $1.43(0.93-2.22)$ & 0.107 & 24 & $1.22(0.72-2.07)$ & 0.460 & $1.27(0.64-2.53)$ & 0.488 \\
\hline \multirow{2}{*}{ NO } & No & 63 & 1.00 & & 1.00 & & 37 & 1.00 & & 1.00 & \\
\hline & OC & 26 & $0.77(0.49-1.22)$ & 0.271 & $1.17(0.67-2.03)$ & 0.582 & 18 & $0.93(0.52-1.66)$ & 0.811 & $0.90(0.43-1.88)$ & 0.780 \\
\hline \multirow{2}{*}{ N1 \& N2 } & No & 43 & 1.00 & & 1.00 & & 17 & 1.00 & & 1.00 & \\
\hline & OC & 30 & $1.38(0.86-2.20)$ & 0.181 & $1.81(1.00-3.28)$ & 0.051 & 12 & $1.20(0.57-2.52)$ & 0.630 & $1.00(0.39-2.56)$ & 1.000 \\
\hline \multirow{2}{*}{ MO } & No & 88 & 1.00 & & 1.00 & & 57 & 1.00 & & 1.00 & \\
\hline & OC & 47 & $1.05(0.73-1.49)$ & 0.804 & $1.55(1.00-2.40)$ & 0.050 & 31 & $1.00(0.64-1.56)$ & 0.999 & $0.83(0.47-1.45)$ & 0.507 \\
\hline \multirow{2}{*}{ M1 } & No & 26 & 1.00 & & 1.00 & & 9 & 1.00 & & 1.00 & \\
\hline & OC & 12 & $0.90(0.45-1.80)$ & 0.771 & $0.96(0.41-2.30)$ & 0.955 & 5 & $1.09(0.35-3.36)$ & 0.880 & $1.75(0.44-6.86)$ & 0.425 \\
\hline \multirow{2}{*}{ beta-catenin+ } & No & 56 & 1.00 & & 1.00 & & 43 & 1.00 & & 1.00 & \\
\hline & OC & 24 & $0.84(0.52-1.37)$ & 0.489 & $1.36(0.75-2.47)$ & 0.308 & 24 & $1.02(0.62-1.70)$ & 0.931 & $1.00(0.53-1.88)$ & 1.000 \\
\hline \multirow{2}{*}{ beta-catenin- } & No & 45 & 1.00 & & 1.00 & & 14 & 1.00 & & 1.00 & \\
\hline & $\mathrm{OC}$ & 29 & $1.27(0.79-2.03)$ & 0.322 & $1.70(0.97-3.00)$ & 0.065 & 10 & $1.41(0.61-3.24)$ & 0.421 & $1.00(0.35-2.87)$ & 1.000 \\
\hline \multirow{2}{*}{ cyclin D1+ } & No & 88 & 1.00 & & 1.00 & & 44 & 1.00 & & 1.00 & \\
\hline & OC & 46 & $1.04(0.72-1.47)$ & 0.843 & $1.62(1.04-2.51)$ & 0.032 & 24 & $1.06(0.64-1.76)$ & 0.826 & $1.04(0.56-1.95)$ & 0.893 \\
\hline \multirow{2}{*}{ cyclin D1- } & No & 15 & 1.00 & & 1.00 & & 14 & 1.00 & & 1.00 & \\
\hline & OC & 8 & $1.00(0.42-2.36)$ & 0.999 & $0.90(0.31-2.60)$ & 0.844 & 7 & $0.82(0.33-2.03)$ & 0.666 & $0.77(0.24-2.48)$ & 0.660 \\
\hline \multirow{2}{*}{ p53+ } & No & 45 & 1.00 & & 1.00 & & 32 & 1.00 & & 1.00 & \\
\hline & OC & 20 & $0.90(0.52-1.53)$ & 0.685 & $1.28(0.67-2.45)$ & 0.451 & 22 & $1.37(0.78-2.39)$ & 0.274 & $1.00(0.49-2.02)$ & 1.000 \\
\hline \multirow{2}{*}{ p53- } & No & 59 & 1.00 & & 1.00 & & 26 & 1.00 & & 1.00 & \\
\hline & OC & 34 & $1.11(0.73-1.70)$ & 0.625 & $1.54(0.90-2.63)$ & 0.115 & 9 & $0.59(0.28-1.27)$ & 0.177 & $0.52(0.21-1.30)$ & 0.161 \\
\hline \multirow{2}{*}{ MSI } & No & 25 & 1.00 & & 1.00 & & 2 & 1.00 & & 1.00 & \\
\hline & OC & 14 & $1.08(0.56-2.09)$ & 0.809 & $1.85(0.82-1.18)$ & 0.139 & 0 & - & & - & \\
\hline \multirow{2}{*}{ MSS } & No & 76 & 1.00 & & 1.00 & & 54 & 1.00 & & 1.00 & 1.000 \\
\hline & OC & 39 & $1.02(0.69-1.50)$ & 0.938 & $1.43(0.89-2.32)$ & 0.143 & 32 & $1.10(0.70-1.72)$ & 0.678 & $1.00(0.58-1.74)$ & \\
\hline
\end{tabular}

Adjusted for age, bmi, educational level, smoking habits and alcohol consumption.

interdisciplanary collaboration and education of epidemiologists in molecular pathology, and pathologists in epidemiology and biostatistics, this interdisciplinary field of MPE can be further elaborated. Along with the well described CIN, MSI and DNA methylation pathways of colorectal carcinogenesis, it has further been proposed that other systems and pathways are involved in the pathogenesis of CRC, such as inflammation, and that microRNAs can actively contribute to the carcinogenic process [53].

\section{Conclusions}

In conclusion, our findings provide information on the relationship between use of hormone replacement therapy and oral contraceptives, and risk of colorectal cancer according to several clinicopathological and molecular subsets of the disease, also depending on tumour location. These findings underline the need for continous investigation and further translational research addressing the effects of hormone therapy on key molecular events underlying the different pathways of colorectal carcinogenesis.

\section{Abbreviations}

CRC: Colorectal cancer; HRT: Hormone replacement therapy;

CHRT: Combined hormone replacemnet therapy; ERT: Oestrogen replacement therapy; OC: Oral contraceptive; MSI: Microsatellite instability; MSS: Microsatellite stability; CIMP: CpG island methylator phenotype; 
MDCS: Malmö Diet and Cancer Study; BMI: Body mass index; TMA: Tissue microarray.

\section{Competing interests}

The authors declare that no competing interests exist.

\section{Authors' contributions}

JB performed all the statistical analyses and drafted the manuscript. SW collected clinical data and evaluated the immunohistochemical stainings. BN constructed the TMAs and carried out all IHC stainings. JE assisted with the collection of clinical data. KJ carried out the histopathological re-evaluation, evaluated the immunohistochemistry, and helped draft the manuscript. JM conceieved of the study, helped with the statistical analyses and helped draft the manuscript. All authors read and approved the final manuscript.

\section{Acknowledgments}

This study was supported by grants from the Knut and Alice Wallenberg Foundation, the Swedish Cancer Society, the Gunnar Nilsson Cancer Foundation, the Swedish Government Grant for Clinical Research, Lund University Faculty of Medicine and Skåne University Hospital Research Grants.

\section{Author details}

'Department of Clinical Sciences, Lund, Oncology and Pathology, Lund University, Skåne University Hospital, Lund, Sweden. ${ }^{2}$ Department of Surgery, Skåne University Hospital, Malmö, Sweden. ${ }^{3}$ Department of Clinical Sciences, Malmö, Lund University, Skåne University Hospital, Malmö, Sweden. ${ }^{4}$ Department of Plastic Surgery, Skåne University Hospital, Malmö, Sweden.

Received: 19 August 2013 Accepted: 21 May 2014

Published: 25 May 2014

\section{References}

1. Jemal A, Bray F, Center MM, Ferlay J, Ward E, Forman D: Global cancer statistics. CA Cancer J Clin 2011, 61(2):69-90.

2. Ogino S, Stampfer M: Lifestyle factors and microsatellite instability in colorectal cancer: the evolving field of molecular pathological epidemiology. J Natl Cancer Inst 2010, 102(6):365-367.

3. Grodstein F, Newcomb PA, Stampfer MJ: Postmenopausal hormone therapy and the risk of colorectal cancer: a review and meta-analysis. Am J Med 1999, 106(5):574-582.

4. Rossouw JE, Anderson GL, Prentice RL, LaCroix AZ, Kooperberg C, Stefanick ML, Jackson RD, Beresford SA, Howard BV, Johnson KC, Kotchen JM, Ockene $\mathrm{J}$ : Risks and benefits of estrogen plus progestin in healthy postmenopausal women: principal results From the Women's Health Initiative randomized controlled trial. JAMA 2002, 288(3):321-333.

5. Chlebowski RT, Wactawski-Wende J, Ritenbaugh C, Hubbell FA, Ascensao J, Rodabough RJ, Rosenberg CA, Taylor VM, Harris R, Chen C, Adams-Campbell $L L$, White E: Estrogen plus progestin and colorectal cancer in postmenopausal women. N Engl J Med 2004, 350(10):991-1004.

6. Delellis Henderson K, Duan L, Sullivan-Halley J, Ma H, Clarke CA, Neuhausen SL, Templeman C, Bernstein L: Menopausal hormone therapy use and risk of invasive colon cancer: the California Teachers Study. Am J Epidemiol 2010, 171(4):415-425.

7. Nelson HD, Humphrey LL, Nygren P, Teutsch SM, Allan JD: Postmenopausal hormone replacement therapy: scientific review. JAMA 2002, 288(7):872-881.

8. Armaghany T, Wilson JD, Chu Q, Mills G: Genetic alterations in colorectal cancer. Gastrointest Cancer Res 2012, 5(1):19-27.

9. Pancione M, Remo A, Colantuoni V: Genetic and epigenetic events generate multiple pathways in colorectal cancer progression. Patholog Res Int 2012, 2012:509348.

10. Brabletz $T$, Jung A, Kirchner T: Beta-catenin and the morphogenesis of colorectal cancer. Virchows Arch 2002, 441(1):1-11.

11. Arber N, Hibshoosh H, Moss SF, Sutter T, Zhang Y, Begg M, Wang S, Weinstein IB, Holt PR: Increased expression of cyclin D1 is an early event in multistage colorectal carcinogenesis. Gastroenterology 1996, 110(3):669-674.

12. Baker SJ, Markowitz S, Fearon ER, Willson JK, Vogelstein B: Suppression of human colorectal carcinoma cell growth by wild-type p53. Science 1990 249(4971):912-915.
13. Liu B, Nicolaides NC, Markowitz S, Willson JK, Parsons RE, Jen J, Papadopolous N, Peltomaki P, de la Chapelle A, Hamilton SR, Kinzler KW, Vogelstein B: Mismatch repair gene defects in sporadic colorectal cancers with microsatellite instability. Nat Genet 1995, 9(1):48-55.

14. Ogino S, Chan AT, Fuchs CS, Giovannucci E: Molecular pathological epidemiology of colorectal neoplasia: an emerging transdisciplinary and interdisciplinary field. Gut 2011, 60(3):397-411.

15. Limsui $D$, Vierkant RA, Tillmans LS, Wang $A H$, Weisenberger DJ, Laird PW, Lynch CF, Anderson KE, French AJ, Haile RW, Harnack LJ, Potter JD, Slager SL, Smyrk TC, Thibodeau SN, Cerhan JR, Limburg PJ: Postmenopausal hormone therapy and colorectal cancer risk by molecularly defined subtypes among older women. Gut 2012, 61(9):1299-1305.

16. Slattery ML, Potter JD, Curtin K, Edwards S, Ma KN, Anderson K, Schaffer D, Samowitz WS: Estrogens reduce and withdrawal of estrogens increase risk of microsatellite instability-positive colon cancer. Cancer Res 2001, 61(1):126-130.

17. Wu AH, Siegmund KD, Long TI, Cozen W, Wan P, Tseng CC, Shibata D, Laird PW: Hormone therapy, DNA methylation and colon cancer. Carcinogenesis 2010, 31(6):1060-1067.

18. McMichael AJ, Potter JD: Reproduction, endogenous and exogenous sex hormones, and colon cancer: a review and hypothesis. J Natl Cancer Inst 1980, 65(6):1201-1207.

19. Fernandez E, La Vecchia C, Franceschi S, Braga C, Talamini R, Negri E, Parazzini F: Oral contraceptive use and risk of colorectal cancer. Epidemiology 1998, 9(3):295-300.

20. Campbell PT, Newcomb P, Gallinger S, Cotterchio M, McLaughlin JR: Exogenous hormones and colorectal cancer risk in Canada: associations stratified by clinically defined familial risk of cancer. Cancer Causes Control 2007, 18(7):723-733.

21. Nichols HB, Trentham-Dietz A, Hampton JM, Newcomb PA: Oral contraceptive use, reproductive factors, and colorectal cancer risk: findings from Wisconsin. Cancer Epidemiol Biomarkers Prev 2005, 14(5):1212-1218.

22. Lin J, Zhang SM, Cook NR, Manson JE, Buring JE, Lee IM: Oral contraceptives, reproductive factors, and risk of colorectal cancer among women in a prospective cohort study. Am J Epidemiol 2007, 165(7):794-801.

23. Weiss NS, Daling JR, Chow WH: Incidence of cancer of the large bowel in women in relation to reproductive and hormonal factors. $J$ Natl Cancer Inst 1981, 67(1):57-60.

24. Jacobs EJ, White E, Weiss NS: Exogenous hormones, reproductive history, and colon cancer (Seattle, Washington, USA). Cancer Causes Control 1994, 5(4):359-366.

25. Levi F, Pasche C, Lucchini F, La Vecchia C: Oral contraceptives and colorectal cancer. Dig Liver Dis 2003, 35(2):85-87.

26. Purdue MP, Mink PJ, Hartge P, Huang WY, Buys S, Hayes RB: Hormone replacement therapy, reproductive history, and colorectal adenomas: data from the Prostate, Lung, Colorectal and Ovarian (PLCO) Cancer Screening Trial (United States). Cancer Causes Control 2005, 16(8):965-973.

27. Bosetti C, Bravi F, Negri E, La Vecchia C: Oral contraceptives and colorectal cancer risk: a systematic review and meta-analysis. Hum Reprod Update 2009, 15(5):489-498.

28. Manjer J, Carlsson S, Elmstahl S, Gullberg B, Janzon L, Lindstrom M, Mattisson I, Berglund G: The Malmo Diet and Cancer Study: representativity, cancer incidence and mortality in participants and non-participants. Eur J Cancer Prev 2001, 10(6):489-499.

29. Larsson A, Johansson ME, Wangefjord S, Gaber A, Nodin B, Kucharzewska P, Welinder C, Belting M, Eberhard J, Johnsson A, Uhlen M, Jirstrom K: Overexpression of podocalyxin-like protein is an independent factor of poor prognosis in colorectal cancer. Br J Cancer 2011, 105(5):666-672.

30. Wangefjord S, Manjer J, Gaber A, Nodin B, Eberhard J, Jirstrom K: Cyclin D1 expression in colorectal cancer is a favorable prognostic factor in men but not in women in a prospective, population-based cohort study. Biol Sex Differ 2011, 2:10.

31. Brandstedt J, Wangefjord S, Nodin B, Gaber A, Manjer J, Jirstrom K: Gender, anthropometric factors and risk of colorectal cancer with particular reference to tumour location and TNM stage: a cohort study. Bio/ Sex Differ 2012, 3(1):23.

32. Eberhard J, Gaber A, Wangefjord S, Nodin B, Uhlen M, Ericson Lindquist K, Jirstrom $\mathrm{K}: \mathrm{A}$ cohort study of the prognostic and treatment predictive value of SATB2 expression in colorectal cancer. Br J Cancer 2012, 106(5):931-938. 
33. Nodin $B$, Johannesson $H$, Wangefjord $S$, O'Connor DP, Lindquist KE, Uhlen M, Jirstrom K, Eberhard J: Molecular correlates and prognostic significance of SATB1 expression in colorectal cancer. Diagn Pathol 2012, 7:115.

34. Wangefjord S, Brandstedt J, Ericson Lindquist K, Nodin B, Jirstrom K, Eberhard J: Associations of beta-catenin alterations and MSI screening status with expression of key cell cycle regulating proteins and survival from colorectal cancer. Diagn Pathol 2013, 8(1):10.

35. Katz MH, Hauck WW: Proportional hazards (Cox) regression. J Gen Intern Med 1993, 8(12):702-711.

36. Calle EE, Miracle-McMahill HL, Thun MJ, Heath CW Jr: Estrogen replacement therapy and risk of fatal colon cancer in a prospective cohort of postmenopausal women. J Natl Cancer Inst 1995, 87(7):517-523.

37. Newcomb PA, Storer BE: Postmenopausal hormone use and risk of large-bowel cancer. J Natl Cancer Inst 1995, 87(14):1067-1071.

38. Wu AH, Paganini-Hill A, Ross RK, Henderson BE: Alcohol, physical activity and other risk factors for colorectal cancer: a prospective study. Br J Cancer 1987, 55(6):687-694.

39. Chute CG, Willett WC, Colditz GA, Stampfer MJ, Rosner B, Speizer FE: A prospective study of reproductive history and exogenous estrogens on the risk of colorectal cancer in women. Epidemiology 1991, 2(3):201-207.

40. Simon MS, Chlebowski RT, Wactawski-Wende J, Johnson KC, Muskovitz A, Kato I, Young A, Hubbell FA, Prentice RL: Estrogen plus progestin and colorectal cancer incidence and mortality. J Clin Oncol 2012 30(32):3983-3990.

41. Tsilidis KK, Allen NE, Key TJ, Sanjoaquin MA, Bakken K, Berrino F, Fournier A Lund E, Overvad K, Olsen A, Olsen A, Tjønneland A, Byrnes G, Chajes V, Rinaldi S, Boutron-Ruault MC, Clavel-Chapelon F, Chang-Claude J, Kaaks R, Bergmann M, Boeing H, Koumantaki Y, Palli D, Pala V, Panico S, Tumino R, Vineis $P$, Bas Bueno-de-Mesquita $H$, van Duijnhoven FJ, van Gils $\mathrm{CH}$, Peeters $\mathrm{PH}$, et al: Menopausal hormone therapy and risk of colorectal cancer in the European Prospective Investigation into Cancer and Nutrition. Int J Cancer 2011, 128(8):1881-1889.

42. Hoffmeister M, Raum E, Winter J, Chang-Claude J, Brenner H: Hormone replacement therapy, body mass, and the risk of colorectal cancer among postmenopausal women from Germany. Br J Cancer 2007, 97(11):1486-1492.

43. Grodstein F, Martinez ME, Platz EA, Giovannucci E, Colditz GA, Kautzky M, Fuchs C, Stampfer MJ: Postmenopausal hormone use and risk for colorectal cancer and adenoma. Ann Intern Med 1998, 128(9):705-712.

44. Lin JH, Morikawa T, Chan AT, Kuchiba A, Shima K, Nosho K, Kirkner G, Zhang SM, Manson JE, Giovannucci E, Fuchs CS, Ogino S: Postmenopausal hormone therapy is associated with a reduced risk of colorectal cancer lacking CDKN1A expression. Cancer Res 2012, 72(12):3020-3028.

45. Newcomb PA, Zheng Y, Chia VM, Morimoto LM, Doria-Rose VP, Templeton A, Thibodeau SN, Potter JD: Estrogen plus progestin use, microsatellite instability, and the risk of colorectal cancer in women. Cancer Res 2007, 67(15):7534-7539.

46. Slattery ML, Curtin K, Anderson K, Ma KN, Ballard L, Edwards S, Schaffer D, Potter J, Leppert M, Samowitz WS: Associations between cigarette smoking, lifestyle factors, and microsatellite instability in colon tumors. J Natl Cancer Inst 2000, 92(22):1831-1836.

47. Morikawa T, Kuchiba A, Yamauchi M, Meyerhardt JA, Shima K, Nosho K, Chan AT, Giovannucci E, Fuchs CS, Ogino S: Association of CTNNB1 (beta-catenin) alterations, body mass index, and physical activity with survival in patients with colorectal cancer. JAMA 2011, 305(16):1685-1694.

48. Carothers AM, Hughes SA, Ortega D, Bertagnolli MM: 2-Methoxyestradiol induces p53-associated apoptosis of colorectal cancer cells. Cancer Lett 2002, 187(1-2):77-86.

49. Hsu HH, Cheng SF, Wu CC, Chu CH, Weng YJ, Lin CS, Lee SD, Wu HC, Huang CY, Kuo WW: Apoptotic effects of over-expressed estrogen receptor-beta on LoVo colon cancer cell is mediated by p53 signalings in a ligand-dependent manner. Chin J Physiol 2006, 49(2):110-116.

50. Jin P, Lu XJ, Sheng JQ, Fu L, Meng XM, Wang X, Shi TP, Li SR, Rao J: Estrogen stimulates the expression of mismatch repair gene $\mathrm{hMLH} 1$ in colonic epithelial cells. Cancer Prev Res (Phila) 2010, 3(8):910-916.

51. Issa JP: Colon cancer: it's CIN or CIMP. Clin Cancer Res 2008, 14(19):5939-5940.
52. Ogino S, Giovannucci E: Commentary: Lifestyle factors and colorectal cancer microsatellite instability-molecular pathological epidemiology science, based on unique tumour principle. Int J Epidemiol 2012, 41(4):1072-1074

53. Colussi D, Brandi G, Bazzoli F, Ricciardiello L: Molecular pathways involved in colorectal cancer: implications for disease behavior and prevention. Int J Mol Sci 2013, 14(8):16365-16385.

doi:10.1186/1471-2407-14-371

Cite this article as: Brändstedt et al: Associations of hormone replacement therapy and oral contraceptives with risk of colorectal cancer defined by clinicopathological factors, beta-catenin alterations, expression of cyclin D1, p53, and microsatellite-instability. BMC Cancer $201414: 371$.

\section{Submit your next manuscript to BioMed Central and take full advantage of:}

- Convenient online submission

- Thorough peer review

- No space constraints or color figure charges

- Immediate publication on acceptance

- Inclusion in PubMed, CAS, Scopus and Google Scholar

- Research which is freely available for redistribution 